F. ZHOU, T. FU, Q. HUANG, H. KUAI, L. MO, H. LIU, Q. WANG, Y. PENG, D. HAN, Z. ZHAO*, X. FANG*, W. TAN* (HUNAN UNIVERSITY, CHANGSHA, INSTITUTE OF CHEMISTRY, CHINESE ACADEMY OF SCIENCES, BEIJING, UNIVERSITY OF CHINESE ACADEMY OF SCIENCES, HANGZHOU AND SHANGHAI JIAO TONG UNIVERSITY, P. R. OF CHINA) Hypoxia-Activated PEGylated Conditional Aptamer/Antibody for Cancer Imaging with Improved Specificity J. Am. Chem. Soc. 2019, 141, 18421-18427.

\section{Caged Aptamers for Improved Cancer Imaging}
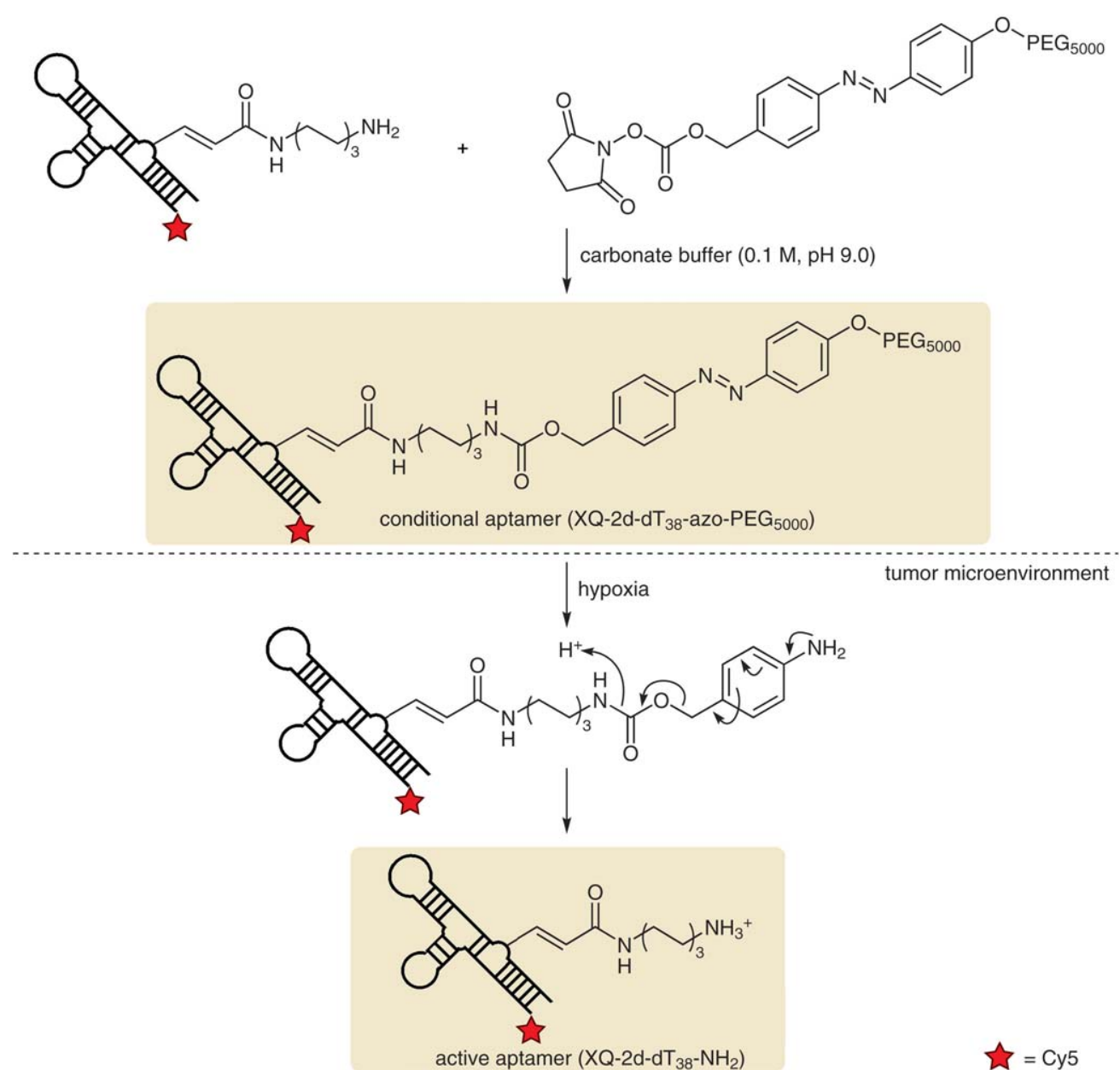

\section{Category}

Chemistry in

Medicine and Biology

\section{Key words}

aptamers

caging

cancer

azobenzenes

imaging

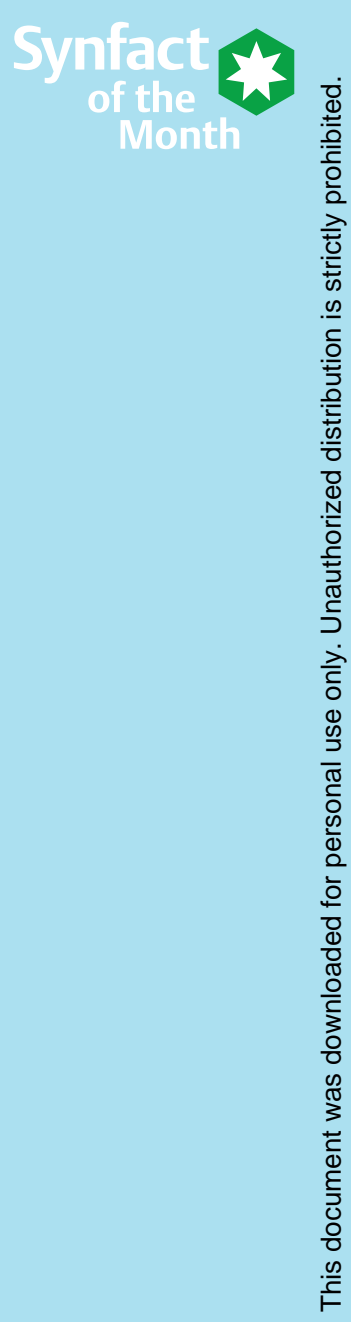

Significance: Aptamers and antibodies are widely used as probes in tumor imaging. Recognition of the tumor by aptamers is based on overexpression of their targets in cancer cells, not target exclusivity. Here, the authors present a strategy to increase the specificity of aptamers by designing a conditional aptamer. Upon exposure to the tumor microenvironment the aptamer is liberated and able to bind its target, thus leading to higher recognition selectivity.
Comment: The authors conjugated an azobenzene-linked $\mathrm{PEG}_{5000}$ chain as a steric blocking group to the aptamer XQ-2d. The azobenzene functions as a redox-sensitive caging unit. When exposed to hypoxia in the tumor microenvironment the azobenzene is cleaved, liberating the active aptamer close to the tumor. The authors demonstrate that this strategy can also be applied to antibodies. 